\title{
Pathological Studies on the Endocrine Organs of the Spontaneously Hypertensive Rats
}

\author{
Kyuzo Aoki, M.D., Hidemitsu Tankawa, M.D., Takao Fujinami, M.D., \\ akio Miyazaki, M.D., and Yoshiteru Hashimoto, M.D.
}

$\mathbf{I}^{\mathrm{T}}$ $T$ is well known that hypertension can be induced experimentally by means of administration of the anterior pituitary powder, ${ }^{1)-3)}$ various corticoids, ${ }^{4)-11)}$ thyroid hormones ${ }^{2)}, 12$ ) and by regeneration of the adrenal cortex after enucleation, ${ }^{13)}$ and that the removal ${ }^{14)-22)}$ and hypofunctioning state $^{20), 23)}$ of endocrine organs prevent the development of these experimental hypertension or lower the established hypertension to the normal range of blood pressure.

Hypertension is clinically present in Cushing's syndrome, ${ }^{24)}$ primary aldosteronism ${ }^{25)}$ and hyperthyroidism. ${ }^{26}$ ) The increased urinary excretion of aldosterone ${ }^{27)}$ has been reported in the malignant hyertension. Hypertrophy of the adrenal cortex and increased content of lipids in the gland ${ }^{28)-31)}$ are known to be present in hypertensive patients. In case of renal hypertension in rats, hypertrophy and an increased content of lipids in the adrenals ${ }^{1}$ as well as hyperactivity of the thyroid, ${ }^{32)}$ and in case of adrenal regeneration hypertension in rats an increased number of basophils ${ }^{18}$ in the pituitary is said to be present.

These experimental observations indicate that various endocrine glands are intimately related to the regulation of experimental as human hypertension. The studies concerning the action of the pituitary and thyroid in the human essential hypertension are, however, scarce. And there is no report dealing with the sequential histological changes of various endocrine organs through the course of prehypertensive to established hypertensive stage. Therefore, much knowledge may be obtained by studying hypertensive animals ${ }^{33)-42)}$ that have many features common to those of human essential hypertension.

Recently, Okamoto and Aoki ${ }^{33}$ ) have succeeded in separating a strain from Wistar rats that gives rise to spontaneous hypertension with $100 \%$ incidence, and called them "spontaneously hypertensive rats (Okamoto and A.oki)." Because of the fact that hypertension occurs spontaneously in their

Department of Pathology (Director: Prof. Kozo Okamoto), Kyoto University School of Medicine, Kyoto, Japan. 
offsprings, this hypertension appears to be comparable to human essential hypertension. Up to the present, few animals with such spontaneous hypertension have been obtained, except only for "inherited hypertension in rats" by Smirk et al., 37)-39) and "spontaneously hypertensive rabbits" by Alexander et al.40),41) They also regarded the spontaneous hypertension of these animals similar to human essential hypertension. But they ${ }^{37)}{ }^{-42}$ ) have not performed detailed studies on endocrine organs of these animals.

The present study is to investigate the role of the endocrine organs in the development and maintenance of hypertersion. The histological and histometrical examination were made in the endocrine organs such as the pituitary, adrenals, thyroid, Langerhans' islets and gonads at various stages of the development of hypertension.

\section{Materials}

The rats of the control groups were first supplied by the Animal Center Laboratory, Kyoto University School of Medicine. These weanling Wistar rats were housed and mated among continuously normotensive (below $149 \mathrm{~mm} . \mathrm{Hg}$ ) animals in the Department of Pathology under normal conditions. Only normotensive offsprings were selected for the control $(\mathrm{N})$.

The hypertensive groups $(\mathrm{H})$ consisted of $F_{3}$ to $F_{6}$ rats of spontaneously hypertensive rats (Okamoto and Aoki). ${ }^{33)}$ Although the method of separation of spontaneously hypertensive rats, their body weight and blood pressure have been already reported, ${ }^{33)}$ a brief note will be made here.

Many weanling Wistar rats supplied by the Animal Center Laboratory, Kyoto University School of Medicine were housed in the Department of Pathology under normal conditions. One male rat with spontaneous hypertension (blood pressure exceeding $150 \mathrm{~mm} . \mathrm{Hg}$ ) persisting for more than one month and a female rat with blood pressures slightly above the average were selected and mated to obtain $F_{1}$ rats. Of the $F_{1}$ rats, males and females with hypertension persisting for more than a month were mated to produce $F_{2}$ rats. The procedure was repeated to obtain $F_{6}$ rats. All the $F_{3}$ to $F_{6}$ rats developed hypertension spontaneously within 15 weeks of age.

A total of 125 rats were used in this study. All rats were killed at various intervals by decapitation; at 40-50 days of age ( $40 \mathrm{D}$ group), $4-5$ months ( $4 \mathrm{M}$ group) and 12-14 months (12 $\mathrm{M}$ group). In the $\mathrm{N}$ groups; the $40 \mathrm{D}$ group consisted of 11 male and 10 female rats, $4 \mathrm{M}$ group, of 7 male and 9 female rats and $12 \mathrm{M}$ group, of 8 male and 11 female rats. In the $\mathrm{H}$ groups; the $40 \mathrm{D}$ group consisted of 8 male rats (case numbers, 5073, 5074, 5075, 5082, 5118, 5129,6009,6010) and 8 female $(5126,5137,6007,6008,6018,6019,6031,6032), 4 \mathrm{M}$ group, of 10 male $(3109$, $3111,3125,3137,4085,4093,4094,4139,4140,5048)$ and 10 female $(3129,3147$, $3154,4092,4100,4136,4137,4141,4142,5044)$, and $12 \mathrm{M}$ group, of 12 male (3013, $3019,3046,3049,3051,3064,3096,3126,3134,4005,4007,4021)$ and 21 female $(3008$, $3009,3011,3012,3018,3026,3036,3042,3047,3055,3058,3059,3062,3071,3073,3074$, $3100,4008,4009,4010,4011)$. The HV group consisted of rats with periarteritis nodosa 
or nephrosclerosis shown by macroscopic observation (Male; 3049, 3096, 3126, 3134, 4005. Female; 3008, 3011, 3012, 3042, 3058, 3062, 3073).

All animals were kept in a room with $18^{\circ}$ to $22^{\circ} \mathrm{C}$ of temperature. The diet ${ }^{33)}$ consisted of Manitoba wheat mixed with cooked dried sardine, and seasoned with a little salt and green vegetables. This diet contained about $0.3 \%$ sodium. Tap water was given ad libitum.

\section{Methods}

Goneral examinations:-Body weight and blood pressure of all rats were measured once weekly, beginning at 4 weeks of age to death. Blood pressure (systolic) was taken by the tail-water-plethysmographic method of Williams et al., ${ }^{43)}$ which was slightly modified by Okamoto and Aoki. ${ }^{33}$ ) The animal to be tested was warmed for $10 \mathrm{~min}$. in a box of $38^{\circ} \mathrm{C}$ of temperature. Then its tail was placed in the plastic chamber through the blood pressure cuff $(2 \mathrm{~cm}$. in width) in a thermostat box where the temperature is constantly kept at $37^{\circ} \mathrm{C}^{33}$ The plethysmograph chamber was filled with warm water of $37^{\circ} \mathrm{C}$. The bood pressure was taken without anesthesia. The average of 4 tests was recorded. The deviation in each measurement was not more than $5 \mathrm{~mm} . \mathrm{Hg}$.

Organ weight:-Immediately following necropsy the pituitary, adrenals, thyroid, pancreas and gonads were removed, cleaned of blood, fat and connective tissue, and the pituitary, thyroid and adrenals were weighed on a torsion balance. The pancreas and gonads were weighed on a lever balance. Organ weight was expressed as the ratio of their actual weight to the body weight; organ wt. Gm./body wt. Gm. $\times 100$.

Histologic examination:-The pituitary was fixed in Helly's solution, embedded in paraffin, and cut in horizontal plane. The sections were cut $4 \mu$. in thickness, stained with PAS-orange-G as modified by Wilson and Ezrin. ${ }^{44}$ The adrenals were fixed in $10 \%$ formalin, and the left adrenals was divided into 2 parts in sagittal plane. One of these was embedded in paraffin, cut $4 \mu$. in thickness. The sections were stained with hematoxyline and eosin (H.E stain). From the other half frozen sections were taken and stained with sudan III. The thyroid was fixed in $10 \%$ formalin. The left lobe was divided into 2 parts along its long axis, and the right lobe was similarly cut into 2 pieces across the minor axis. These sections were embedded in paraffin, and cut $4 \mu$. in thickness. They were stained with $\mathrm{H} \cdot \mathrm{E}$. The pancreas was divided into 3 parts; the head, body and tail, fixed in Bouin's solution, embedded, cut and stained with H.E. The gonads were likewise fixed in $10 \%$ formalin, the central portion of the left half was embedded in paraffin, cut and stained with $\mathrm{H} \cdot \mathrm{E}$.

Histometrical examination:--4 $\mu$-thick paraffin sections were used.

Per cent of anterior pituitary calls. The percentage of basophils, eosinophils, chromophobs and undifferentiated cells on sections stained with PAS-orange-G was computed by Rasmussen's method as modified by Inoue. ${ }^{45}$ )

Adrenals:-The areas of the glomerular, fascicular and reticular zones and the medulla in cross-sections stained with $\mathrm{H} \cdot \mathrm{E}$, were traced with an Abbe's projector, to measure the cross-sectional area of each zone with a planimeter. The average 
area was recorded as square $\mu$. (magnification, $\times 4$ ocular and $\times 5$ objective).

Thyroid:-In H.E sections of both lobes 50 follicles were selected at random. The cross-sectional area of individual follicles and their lumens was similarly measured. The average area was expressed in square $\mu$. (mag., 10×40). At the same time, average number of cells per follicle was counted. The average cross-sectional area of the individual follicle cell was obtained as follows. The area of an average follicular lumen was subtracted from that of an average follicle, and the difference was divided by the average cell number of the follicle. The average height of follicle cells was obtained as follows. Twenty-five follicles were selected at random from each lobe. In each follicle thus selected, the height of two opposing cells arbitrarily selected was similarly measured using an Abbe's projector and the average height of the cells was recorded in $\mu$. (mag., $10 \times 100$ ).

Pancreas:-Seven Langerhans' islets were selected each from the hand, body and tail at random in $\mathrm{H}$. E-stained sections. Each area of the islet was similarly measured and expressed in square $\mu$. (mag., $10 \times 20$ ).

Statistical analysis:-The data thus obtained in the normotensive and hypertensive groups were statistically analyzed using " $t$ " test, and the data were considered significant when the " $p$ " values were less than 0.01 .

\section{RESUlts}

All the data from the $\mathrm{H}$ groups were compared with those from the $\mathrm{N}$ groups of the same age and sex.

Body weight:- There was no significant difference between the $\mathrm{H}$ and $\mathrm{N}$ groups (Table I).

Blood pressure:- The average blood pressure of the $\mathrm{N}$ groups remained in the range from 130 to $138 \mathrm{~mm} . \mathrm{Hg}$. In the $\mathrm{H}$ groups, it rose steadily with age and was significantly higher than that in the $\mathrm{N}$ groups. The HV group recorded the highest blood pressure (Table I).

Organ weight:-The ratios of organ weight to body weight are shown in Table I.

Pituitary:-The pituitary in the $H$ groups were heavier than those in the $\mathrm{N}$ groups. The difference was signinicant in the female rats of the $4 \mathrm{M}$, and both sexes of the $12 \mathrm{M}$ groups.

Adrenals:- The adrenal in the $\mathrm{H}$ groups were heavier than those in the $\mathrm{N}$ groups, and the difference was significant in both sexes of the $4 \mathrm{M}$ group, and the female of the $12 \mathrm{M}$ group except in the HV group.

Thyroid:-The thyroid weight in the $4 \mathrm{M}$ and $12 \mathrm{M}$ groups of $\mathrm{H}$ groups were heavier than those in the $\mathrm{N}$ groups and the difference was significant in the female of the $12 \mathrm{M}$ and the male of the $\mathrm{HV}$ group.

Pancreas and gonads:- There was no significant difference of weight between the 2 groups.

As to the age of animals, the organ-body weight ratios of the pitui- 


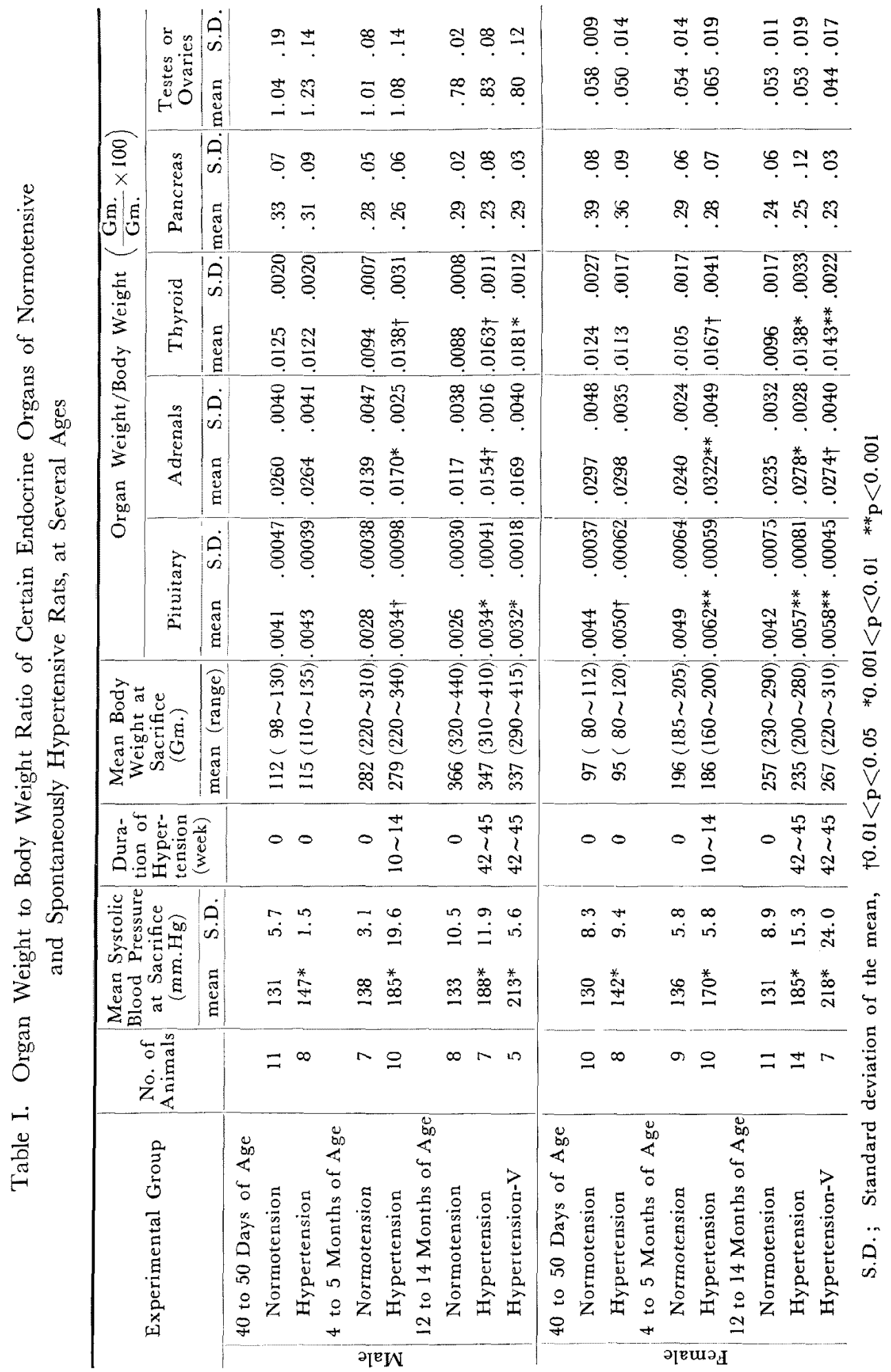


tary, adrenals, thyroid and pancreas were largest in the $40 \mathrm{D}$ group, and were larger in the $4 \mathrm{M}$ group than in the $12 \mathrm{M}$ group, both in the $\mathrm{N}$ and $\mathrm{H}$ groups.

Histological findings:

Pituitary:-In the $\mathbf{H}$ groups, the basophils were increased in number. Their cytoplasm contained more PAS-positive granules than that of the $N$ groups, and the nuclei showed clear nucleic structure. These changes were especially prominent in those of the $4 \mathrm{M}$ and $12 \mathrm{M}$ groups, and hypertrophy and swelling of the cytoplasm of basophils were noted. PAS-positive granules in some of these cells were diminished and replaced by slightly PAS-positive homogeneous substance. Their nuclei were enlarged and oval. These changes were consistent with the hyaline change seen in Gushing's syndrome (Fig. 1, 2). The chromophobs, eosinophils and

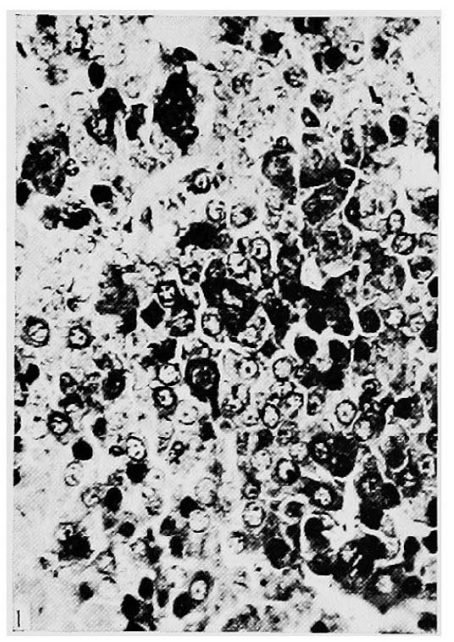

Fig. 1. Central part of anterior pituitary of a normotensive male rat with blood pressure of $142 \mathrm{~mm} . \mathrm{Hg}$ at death, 4 months of age. PAS-orangeG stain. $\times 400$.

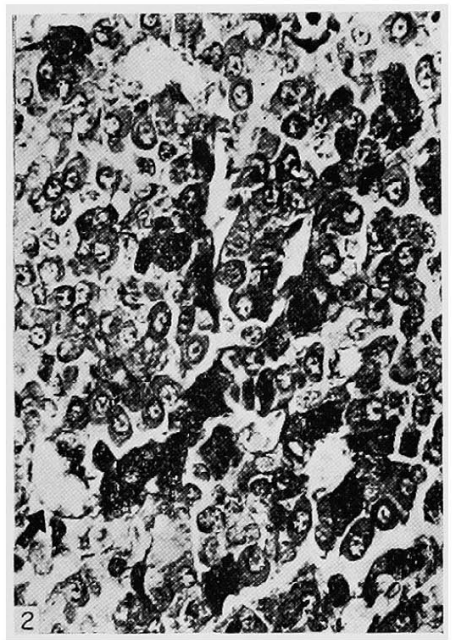

Fig. 2. Central part of anterior pituitary of a spontaneously hypertensive male rat with blood pressure of $192 \mathrm{~mm} . \mathrm{Hg}$ at death, 4 months of age. No. 4094. Basophils are increased and rich in PAS-positive granules in cytoplasm, "hyaline change" is shown (arrow). PAS-orange-G stain. $\times 400$.

undifferentiated cells showed no remarkable changes.

Adrenals:- In the $\mathrm{H}$ groups, the glomerular zone was thick, and the cells were round and large. The cytoplasm was finely vesicular, and contained vacuoles of various size. The nuclei had clear nucleic structure and were large and oval. In the $\mathrm{H}$ groups, the fascicular zone was likewise thick and cell cords became irregular in arrangement and sometimes extended irregularly into the medulla. The cells were large and 
round to elliptical. The cytoplasm had a fine vesicular structure and contained various-sized vacuoles. The nuclei had clear nucleic structure, were large and oval. The reticular zone in $\mathrm{H}$ group was narrowed (Fig. 3-5). The vacuoles in the cytoplasm of the outer 2 layers were filled

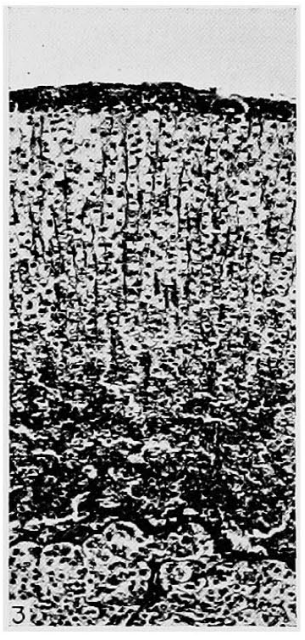

Fig. 3. Adrenal of a normotensive female rat with blood pressure of $138 \mathrm{~mm} . \mathrm{Hg}$ at death, 12 months of age. $\mathrm{H} \cdot \mathrm{E}$ stain. $\times 100$

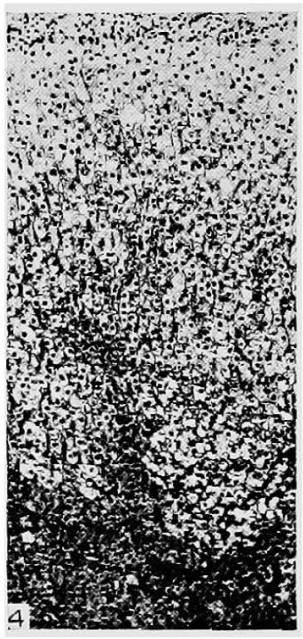

Fig. 4. Adrenal of a spontaneously hypertensive female rat with blood pressure of $200 \mathrm{~mm} . \mathrm{Hg}$ at death, 12 months of age. No. 3074. The reticular and fascicular zone are thickened, and cell cords are irregular. $\mathrm{H} \cdot \mathrm{E}$ stain. $\times 100$.

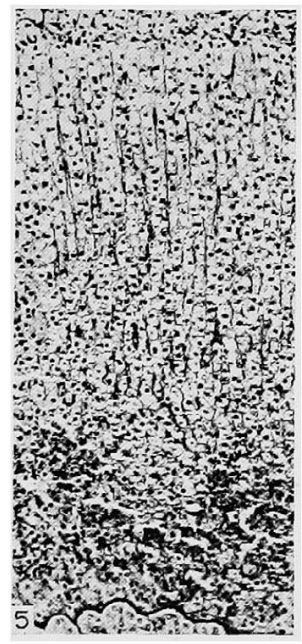

Fig. 5. Adrenal of spontaneously hypertensive female rat with blood pressure of $200 \mathrm{~mm} . \mathrm{Hg}$ at death, with periarteritis nodosa, 14 months of age. No. 3062 (HV group). The reticular and fascicular zones are thickened, the cells are round and have finely vesicular cytoplasm. 
with sudanophilic material. In comparison with the $\mathrm{N}$ groups, the increase in lipids was most remarkable in the glomerular zone and moderate in the fascicular zone (Fig. 6-8). These hyperplastic changes were slight

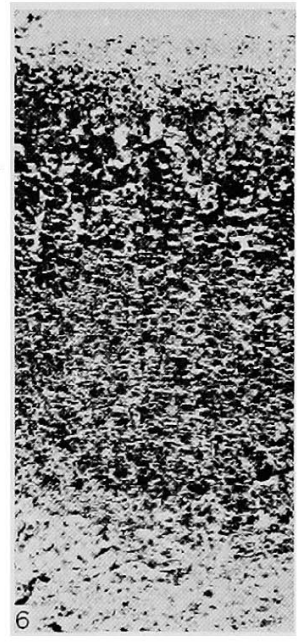

Fig. 6. Adrenal of a normotensive female rat. From the same animal as in Fig. 3. Sudan III stain.

$\times 100$.

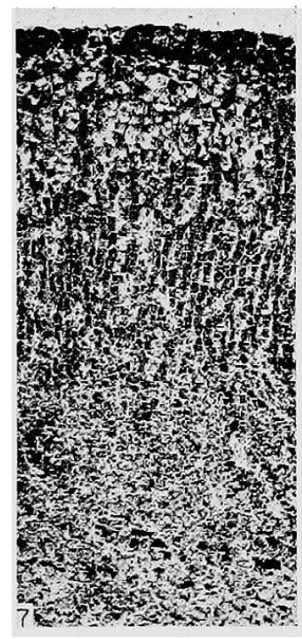

Fig. 7. Adrenal of a female spontaneously hypertensive rat. No. 3074. The sudanophilic granules are increased in the glomerular and fascicular zones. Sudan III stain. $\times 100$.

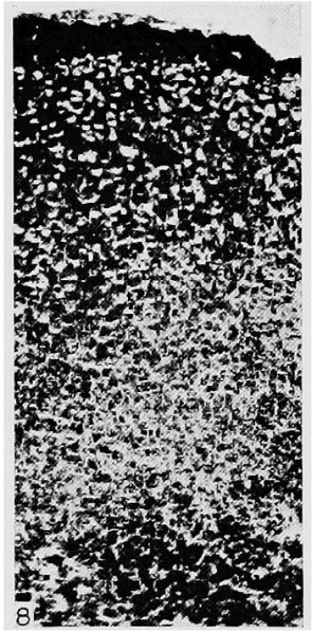

Fig. 8. Adrenal of a spontaneously hypertensive female rat. No. 3062. The sudanophilic granules are increased in the glomerular and fascicular zones. Sudan III stain. $\times 100$.

in the $40 \mathrm{D}$, moderate in the $4 \mathrm{M}$, remarkable in the $12 \mathrm{M}$ group and most remarkable in the $\mathrm{HV}$ group. 
Thyroid:- In the $\mathrm{H}$ groups the follicles were enlarged in general and varied in size with occasional intraluminal papillary projections. The follicle cells were columnar and contained minute cytoplasmic vacuoles. The nuclei were oval, distinct in nucleic structure, and were placed close to the base. The colloid substance was scanty, nubecular, and usually stained slightly eosinophilic. The capillaries in the interstitium were somewhat dilated, but no proliferation of connective tissue or infiltration of cells were observed. These changes were more apparent in the $4 \mathrm{M}$ and $12 \mathrm{M}$ groups than in the $40 \mathrm{D}$ group (Fig. 9-12).

Pancreas and gonads:-No remarkable changes were observed in the $\mathrm{H}$ group as well as in the $\mathrm{N}$ groups.

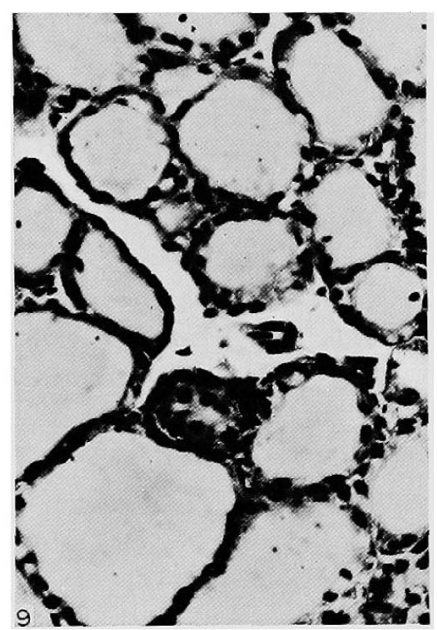

Fig. 9. Thyroid of a normotensive female rat with blood pressure of 124 mm.Hg at death, 47 days of age. The follicles are round, the follicle cells are flat to cuboidal. H.E stain. $\times 400$.

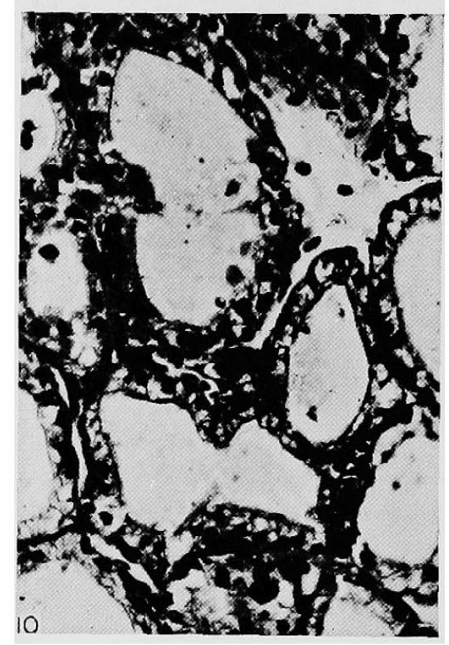

Fig. 10. Thyroid of a spontaneously hypertensive female rat with blood pressure of $145 \mathrm{~mm} . \mathrm{Hg}$ at death, 40 days of age. No. 5137. The follicles are oval. Intraluminal papillary proliferation is noted. The follicle cells are columnar and cytoplasm, vesicular. H.E stain.

$\times 400$.

Histometrical results:- The results are shown in Table II.

Percentage of cells in the anterior lobe of the pituitary:-There was an increase in basophils in the $\mathrm{H}$ groups. The difference between the $\mathrm{H}$ and $\mathrm{N}$ groups was statistically significant in the males of the $40 \mathrm{D}$, and females of $4 \mathrm{M}$ and $12 \mathrm{M}$ groups. However, there was no significant difference in number of eosinophils, chromophobs and undifferentiated cells.

Adrenal cross-sectional area:-The cross sectional area of the glomerular zone in the $\mathrm{H}$ groups was significant in the $12 \mathrm{M}$ groups. The 


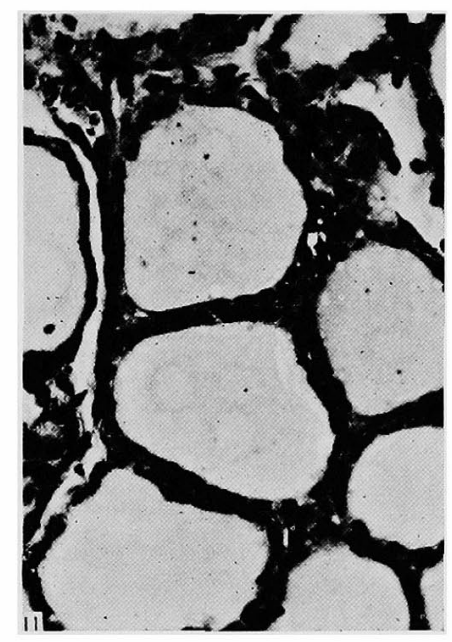

Fig. 11. Thyroid of a normotensive female rat with blood pressure of 128 mm. $\mathrm{Hg}$ at death, 12 months of age. The follicles are round, and the lumen is filled with colloid. H.E stain. $\times 400$.

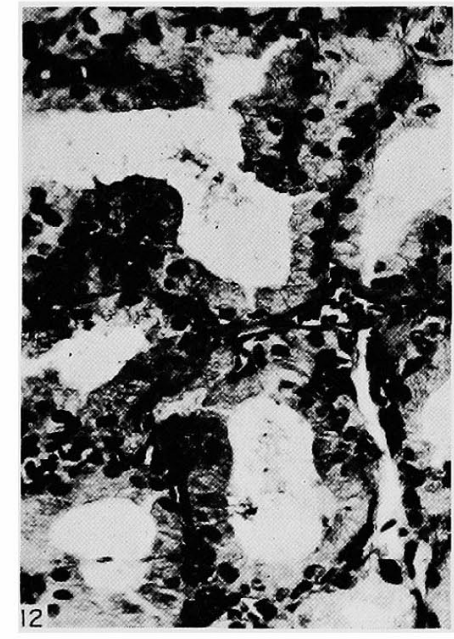

Fig. 12. Thyroid of a spontaneously hypertensive female rat with blood pressure of $195 \mathrm{~mm} . \mathrm{Hg}$ at death, 12 months of age. No. 3059. The follicle are irregularly polygonal. The follicle cells are columnar. Colloid of follicles decreases and appears nubecular. H.E stain.

$\times 400$.

summed cross-sectional area of the fascicular and reticular zones in the $\mathrm{N}$ groups, and the difference were significant in the female of the $4 \mathrm{M}$ and both sexes of the $12 \mathrm{M}$ groups.

Thyroid:-The area of follicles, follicular lumens, and of follicle cells, the follicle cell height and number of cells forming a follicle increased in the $\mathrm{H}$ groups. The differences among the $\mathrm{H}$ and $\mathrm{N}$ groups were significant, in the area of follicles and follicular lumen of the $40 \mathrm{D}, 4 \mathrm{M}$ and $12 \mathrm{M}$ groups, in the area of follicle cells of the male of $40 \mathrm{D}$, and both sexes of the $4 \mathrm{M}$ and $12 \mathrm{M}$ groups, in the follicle cell height of the female of the $40 \mathrm{D}$ and both sexes of the $4 \mathrm{M}$ and $12 \mathrm{M}$ groups, in number of cells forming a follicle of the male of $40 \mathrm{D}$ and $4 \mathrm{M}$ groups.

Area of Langerhans' islet of the pancreas:-There was no remarkable difference in the size of the 2 groups.

\section{Discussion}

It has already been reported by Okamoto and Aoki ${ }^{33)}$ that there is no significant difference in body weight between the animals of the $\mathrm{H}$ and $\mathrm{N}$ groups, and that in the $\mathrm{H}$ group the blood pressure of males is higher than those of females. Moreover, blood pressure rises with age in spon- 


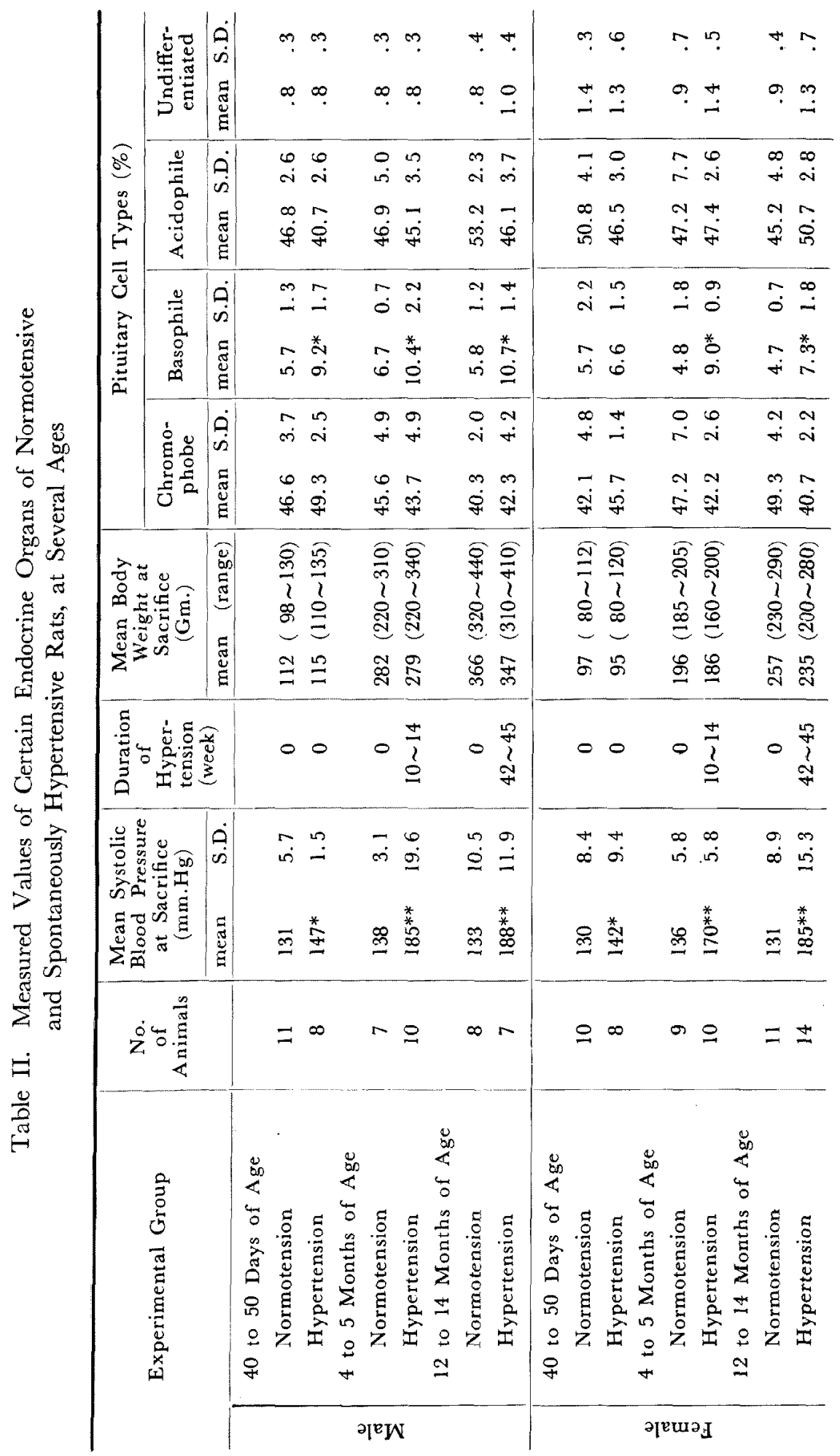




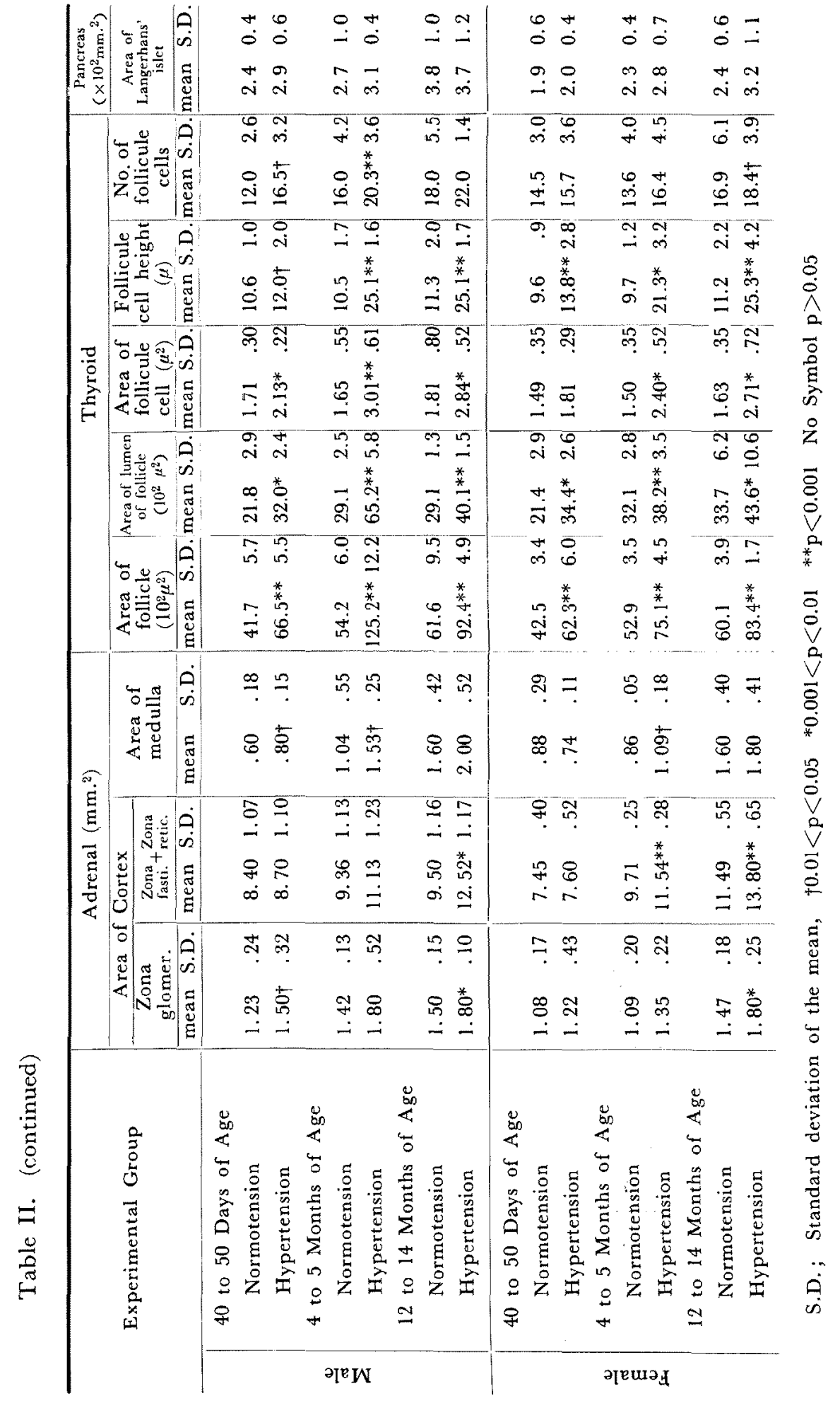


taneously hypertensive rats.

The present experimental results have shown that the pituitary becomes larger and basophils are increased in number, scattered diffusely throughout the anterior lobes of the $\mathrm{H}$ groups. These changes have been noted even at the prehypertensive stage and become remarkable as blood pressure rose. With continued hypertension, hypertrophy and "hyaline change" appeared. These changes resembled those found in the pituitary of patients with Cushing's syndrome ${ }^{24)}$ with hypertension. On the other hand, it has been reported that hypertension can be induced experimentally by the administration of pituitary hormones. ${ }^{1-3)}$ The basophils are considered to secrete $\mathrm{TSH}^{46)}$ and ACTH. ${ }^{47}$ Presence of marked changes in the adrenal cortex but no changes in the gonad in our rats may indicate that a large amount of hormones such as TSH and ACTH are being secreted from the pituitary of these animals, which in turn are taking part in the development and the process of hypertension in the spontaneously hypertensive rats. However, no neoplastic alterations such as adenoma were observed in the pituitary of the hypertensive animals.

In the animals of the $H$ group even at the prehypertensive stage the glomerular zone of the adrenal cortex had hypertrophied and its lipid increased in amount. With maintained hypertension these alterations became marked, at least partly being responsible to increase of the weight of the adrenal gland. It is generally believed that the glomerular zone is the site of aldosterone production.48),49) Therefore, hypersecretion of aldosterone in the $\mathrm{H}$ group is likely to be present. However, it is not clear whether or not this is regulated by the increase in renin release from the juxtaglomerular apparatus. ${ }^{48},{ }_{50)}$,51) At any rate, hypertrophy of the glomerular zone is already present even at the prehypertensive stage and has become gradually remarkable with increasing blood pressure. It is therefore probably true that the hypertrophy of the glomerular zone plays a significant role in the development and maintenance of hypertension. The hypertrophy of the fascicular zone and the increase in its lipid content were observed in the hypertensive animals. Glucocorticoids ${ }^{49}$ are secreted from the fascicular zone and severe hypertension is experimentally induced by the administration of cortisone, $\left.{ }^{7}\right)$ corticosterone $^{5)}$ and hydrocortisone. ${ }^{6)}$ The increase in width of the fascicular zone is observed in the adrenal glands of the animals with adrenal-regeneration hypertension. ${ }^{13)}$ The hypersecretion of glucocorticoids caused by the hypertrophy of the fascicular zone leads to Cushing's syndrome $^{24)}$ which is usually accompanied by hypertension. On the other hand, low sodium diet ${ }^{48}$ induces hypertrophy of the glomerular zone but no hypertension. Therefore, it may be the fascicular zone which plays 
a much more important role in the induction of hypertension. The hypertrophy of the fascicular zone may be secondary to the hyperplasia of the basophils in the pituitary. It could be a primary lesion, or it might be a combined and complicated effect of the first two.

Review of literatures has shown the following fondings; increase in weight of the adrenal gland, ${ }^{52)}{ }^{53}$ ) hypertrophy of the glomerular zone ${ }^{1)}$ and hypertrophy of the fascicular zone, ${ }^{1,}{ }^{\text {,53) }}$ and increase in lipid conten $t^{1)}$,53) of the glomerular and the fascicular zones are present in experimental hypertension. In the essential hypertension of man it is reported that there are an increase in weight of the adrenal gland, ${ }^{28}$ ) hypertrophy of the glomerular and the fascicular zones, the irregularity ${ }^{30}$ of cell cords of the fascicular zone and the increase in lipid content ${ }^{28)}$-30) which is marked in the glomerular zone and moderate in the fascicular zone. These findings reported in many papers are in close accordance with those of the authors' experiments using spontaneously hypertensive rats. According to Deane et al. ${ }^{1)}$ these changes of the adrenal gland result from the alteration of renin secretion, and Dawson ${ }^{28)}$ regarded these changes as the secondary rather than the primary. Fregly ${ }^{5: 3}$ considered them as secondary factors which play an important role in raising blood pressure.

Even before the development of hypertension in the $\mathrm{H}$ group rats various changes are already observed in the thyroid gland including the increase in height and area of follicle cells, in the size and number of cells forming each follicles, intraluminal papillary proliferation of follicular epithelial cells, and the tendency of decrease in amount of colloid. After a long period of hypertension these morbid changes become more marked and the increase in weight of the gland also becomes evident. According to Williams et al. ${ }^{54}$ the histologic pictures characteristic of the hyperactive thyroid are the irregularity in shape of follicles and the tendency of the follicular epithelial cells becoming columnar. On the other hand, Astwood et al. ${ }^{55}$ ) have observed a follicular hypertrophy, hyperplasia of follicular epithelial cells and decrease or entire disappearance of colloid substance from the thyroid glands of the animals to which anti-thyroid substance has been administered, and on these experimental result they concluded that although the follicular epithelial cells have proliferated, the functions of the gland have been much reduced. In the present experiments the animals certainly did not receive any antithyroid drugs. Therefore, the histologic pictures may be considered to show hyperfunction of the gland itself. Thyroxin increases cardiac output, ${ }^{56}$ ) enhances the action of epinephrine and norepinephrine ${ }^{56), 57)}$ on vessels and promotes excretion of potassium. ${ }^{56}$ ) As a result of these actions thyroxin will probably be able to raise blood pressure. As is well known, hypertension 
is frequently encountered in patients with hyperthyroidism. ${ }^{26)}$ From the above mentioned facts, the histological findings observed in the thyroid gland of the animals of the $\mathrm{H}$ groups are compatible with hyperfunctions of the gland which act as a blood pressure raising factor at the prehypertensive stage. These changes of the thyroid may be secondary to the hypersecretion of TSH due to the proliferation of basophils in the pituitary or they could be independent primary lesions. Fregly et al. ${ }^{32}$ believe that the hyperfunction of the thyroid of the rats with renal hypertension plays a secondary role in raising blood pressure.

The pancreas and the gonads of the animals of $\mathrm{H}$ group do not show any noticeable changes.

To sum up these findings, in spontaneously hypertensive rats some definite changes already occur in the pituitary, adrenals and thyroid even at the prehypertensive stage, and after the development of hypertension these changes become more marked. In these processes, however, it can not be determined whether these histologic changes in each organ play a primary etiologic role in development and maintenance of hypertension or they act as secondary factors controlled by the pituitary-adrenal system, pituitary-thyroidal system or reno-adrenal system, or moreover by a higher center such as the diencephalon. Further studies are necessary to clarify this problem.

\section{SUMMARY}

Body weight and blood pressure were measured in the normotensive Wistar rats with the systolic blood pressure below $149 \mathrm{~mm} . \mathrm{Hg}$ and spontaneously hypertensive rats by Okamoto and A.oki. A.nimals, from both groups, were killed at 40-50 days (prehypertensive stage), 4-5 months (after a moderate duration of hypertension), and 12-14 months of ages (after a long duration of hypertension). Endocrine organs were weighed and studied histometrically and histopathologically.

The results in the hypertensive animals were as follows.

(1) Some increases in weight of the pituitary and in the percentage of basophils in the anterior lobe were noted at the prehypertensive stage. These changes were exaggerated as hypertension persisted. The hypertrophy and the change similar to hyaline change were observed in basophils.

(2) In the adrenals, the area of the glomerular zone and the summed area of the fascicular and reticular zones were increased. The hypertrophy and increase in lipid content of the glomerular and fascicular zones were detected even at the prehypertensive stage. With persistence of hypertension these changes became more marked, and increase in weight 
of adrenals, irregularity of cell cords of the fascicular zone, decrease in width of the reticular zone were demonstrated. The increase in lipid content was remarkable in the glomerular zone and moderate in the fascicular zone but more remarkable in groups which were complicated by periarteritis nodosa or nephrosclerosis.

(3) In the thyroid, the increase in area of follicle cells, follicle and lumen, and irregularity in shape of follicles were found at the prehypertensive stage. As hypertension persisted these changes became more remarkable. Weight of the thyroid increased and the colloid content decreased. The histological changes were compatible with that of struma parenchymatosa macrofollicularis.

(4) In the pancreas and gonads, there was no significant difference between the hypertensive and normotensive groups.

(5) The present study has demonstrated that the pituitary anterior lobe, adrenal cortex and thyroid have significant roles in the development and maintenance of hypertension in the spontaneously hypertensive rats.

\section{REFERENGES}

1. Deane, H.W. and Masson, G.M.C.: J. Clin. Endocrinol. 11: 193, 1951 .

2. Handler, P. and Bernheim, F.: Am. J. Physiol. 166: 528, 1951.

3. Masson, G.M.C., Hazard, J.B., Corcoran, A.C., and Page, I.H.: Arch. Path. 49 : $641,1950$.

4. Selye, H. and Pentz, E.I. : Canad. Med. Ass. J. 49: 264, 1943.

5. Skelton, F.R.: Endocrinol. 62: 365, 1958.

6. Friedman, S.M., Friedman, C.L., and Nakashima, M.: Endocrinol. 53: 633, 1953.

7. Knowlton, A.I., Loeb, E.N., Stoerk, H.C., and White, J.P.: J. Exper. Med. 96: $187,1952$.

8. Knowlton, A.I., Loeb, E.N., and Stoerk, H.C.: Endocrinol. 60: 768, 1957.

9. Gornall, A.G., Grundy, H.M., and Koladich, G.J.: Ganad. J. Biochem. Physiol. 38 : 43,1960

10. Gaunt, R., Gross, F., Renzi, A.A., and Chart, J.J.: Hypertension, the first Hahneman symposium on hypertensive disease, 219-232, W.B. Saunders Co., Philadelphia, 1959.

11. Gross, F.: Essential Hypertension, an international symposium, 92-111, SpringerVerlag, Berlin, 1960.

12. Masson, G.M.C., Corcoran, A.C., and Pagc, I.H.: Endocrinol. 61 : 409, 1957.

13. Skelton, F.R.: Physiol. Rev. 39: 162, 1959.

14. Green, D.M., Saunders, F.J., Wahlgren, N., McDonaugh, F.J., and Clampit, J.M. : Am. J. Physiol. 170: 107, 1952.

15. Page, E.W., Ogden, E., and Anderson, E.: Am. J. Physiol. 147: 471, 1946.

16. Skelton, F.R.: Arch. Int. Med. 98: 449, 1956.

17. Goldblatt, H.: The Renal Origin of Hypertension, 37-50, Charles C. Thomas, Springfield, Illinois, 1948.

18. Chappel, C.I., Rona, G., Revesz, C., and Gahill, J.: Proc. Soc. Exp. Biol. Med. 98: $23,1958$.

19. Rondell, P.A.: Univ. Mich. Med. Bull. 27 : 187, 1961. 
20. Sturtevant, F.M.: Ann. Int. Med. $49: 1281,1958$.

21. Williams, W., Whisnant, C., and Fitts, W.T.: Am. J. Physiol. $170: 57,1950$.

22. Fregly, M.J., Gennaro, J.F., and Otis, A.B.: Circulat. Res. 8: 749, 1960.

23. Fregly, M.J. and Cook, K.M.; Acta Endocrinol. 34: 411, 1960.

24. Plotz, C.M., Knowlton, A.I., and Ragan, C.: Am. J. Med. 13 : 597, 1952.

25. Conn, J.W.: Arch. Int. Med. 107. 813, 1961.

26. Williams, R.H. and Bakke, J.L.: Textbook of Endocrinology, 150-196, W.B. Saunders Co., Philadelphia and London, 1962.

27. Laragh, J.H.: Circulation 25: 203, 1962.

28. Dawson, I.M.P.: J. Path. Bact. 72: 393, 1956.

29. Fisher, J.A. and Hewer, T.F.: J. Path. Bact. 59: 605, 1947.

30. Dempsy, W.S.: Arch. Path. 34: 1031, 1942.

31. Bundschu, E.: Frank. Zeit. Path. 67: 517, 1956.

32. Fregly, M.J. and Gonzalez, J.V.: Am. J. Cardiol. 8: 694, 1961.

33. Okamoto, K. and Aoki, K.: Jap. Circulat. J. 27: 282, 1963.

34. Okamoto, K., Aoki, K., and Hashimoto, Y.: Acta Path. Jap. 11 : 249, 1961.

35. Okamoto, K., Aoki, K., Hashimoto, Y., and Suzuki, Y.: Jap. Circulat. J. 26: 646, 1962 (in Japanese).

36. Okamoto, K.: Folia Endocrinol. Jap. 38: 782, 1962 (in Japanese).

37. Smirk, F.H. and Hall, W.H.: Nature 182: 727, 1958.

38. Laverty, R. and Smirk, F.H.: Circulat. Res. 9: 455, 1961.

39. Phelan, E.L., Eryetishir, I., and Smirk, F.H.: Circulat. Res. 10: 817, 1962.

40. Alexander, N., Hinshaw, L.B., and Drury, D.R.: Proc. Soc. Exp. Biol. Med. 86: $855,1954$.

41. Alexander, N., Hinshaw, L.B., and Drury, D.R.: Proc. Soc. Exp. Biol. Med. 92: $249,1956$.

42. Alexander, N., Tibbs, W.J., and Drury, D.R.: Proc. Soc. Exp. Biol, Med. 95: 356, 1957.

43. Williams, J. R., Harrison, T.R., and Grollman, A.: J. Clin. Invest. 18: 373, 1939.

44. Wilson, W.D. and Ezrin, C.: Am. J. Path. 30: 891, 1954.

45. Inoue, T.: Jap. Arch. Int. Med. 3: 908, 1956 (in Japanese).

46. Purves, H.D. and Griesbach, W.E. : Endocrinol. 49: 652, 1951.

47. Marshall, J.M. : J. Exper. Med. 94: 21, 1951.

48. Hartroft, W.S. and Hartroft, P.M. : Fed. Proc. $20: 845,1961$.

49. Stachenko, J. and Giroud, C.J.P.: Endocrinol. 64: 730, 1959.

50. Edelman, R. and Hartroft, P.M.: Circulat. Res. 9: 1069, 1961.

51. Bing, J. and Kazimierczak, J. : Acta Path. Microbiol. Scandiniv. 54: 80, 1962.

52. Fregly, M.J.: Am. J. Physiol. 202: 967, 1962.

53. Rather, L.J.: Am. J. Path. 27: 717, 1951.

54. Williams, R.H. and Bakke, J.L.: Textbook of Endocrinology, 98-100, W.B. Saunders Co., Philadelphia and London, 1962.

55. Astwood, E.B., Sullivan, J., Adele, B., and Jyslowitz, R.: Endocrinol. 32: 210, 1943.

56. Williams, R.H. and Bakke, J.L.: Textbook of Endocrinology, 116-117, W.B. Saunders Co., Philadelphia and London, 1962.

57. Brewster, W.R., Isaacs, J.P., Osgood, P.F., and King, T.L.: Circulation 13: 1, 1956. 